\title{
Building A Business Incubator: A Teaching Case Study
}

Jason T. White, (Email: jwhite@mail.nwmissouri.edu), Northwest Missouri State University J. Patrick McLaughlin, Northwest Missouri State University

\begin{abstract}
The purpose of this case study is to discuss the feasibility of a business incubation facility in an agricultural region of the United States. The paper explains some of the unique characteristics of this environment, and discusses what an incubator might look like in this region. Our research to date indicates that a business incubator facility can not only be a strong engine for economic development and job creation, even rurally, the incubator model creates an environment that greatly improves a new enterprise's chance for success. In small-town America, those successes are incredibly important for economic growth.
\end{abstract}

\section{EXECUTIVE SUMMARY}

Our goal in this paper was to explore some of the challenges and roadblocks encountered as a few project researchers attempt to determine the feasibility of a business incubation facility in a small, rural and agricultural community like ours. A state-of-the-art incubation facility, if located within the central downtown business district, would likely greatly improve the aesthetics of the area, and perhaps draw new business investment into the core of the community. Business incubation facilities create jobs, with the ultimate goal of producing, or graduating, stand-alone companies, capable of self-sustaining operations within a period of about three (3) years. Such economic development activities can be vital in helping rural areas stem the general population loss many have experienced and also potentially lower the rate of rural unemployment and poverty.

\section{INTRODUCTION}

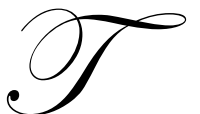

o help the reader understand some of the basic demographics and history of our community, we offer the following summary background information. Our rural town serves as home to a regional university of approximately 6,500 students located in the agricultural Midwest. The university is well established in the region with more than 100 years of educational service to the area. The university's commitment to quality and strategic planning has been recognized regionally, nationally and internationally, and administration and stakeholders have proven to be very receptive to business incubation and innovation center proposals.

The university graduates more than 1,000 students per academic year, yet few remain in our area. Our university community, a town of approximately 11,000 residents, is the county seat and a regional hub of activity in our rural 5-county area, with a high retail pull factor. Our town benefits from an abundance of manufacturing employers in addition to the presence of the university. Three nationally known manufacturing companies have plants, which employ hundreds of area residents. While our workforce is blessed with an unemployment rate that hovers around $1 \%$, and is consistently the lowest in the state and occasionally the nation, there is still a tremendous need in our region for higher wage non-manufacturing types of jobs to more fully develop our community and service the area's needs.

Despite the many positives in the region, some faculty and administrators have noticed a big opportunity for improvement, or "OFI" as we say on our campus. Faculty, staff and students truly embrace the quality movement on campus, and its main decision driver of "continuous improvement." While the employment situation in town is quite 
positive, there are not an abundance of high salary jobs in town, and we also experience a substantial brain drain, as newly educated college graduates leave for greater opportunities in the metropolitan areas. Geographically, the university is located within a corridor that is only a two to three hour drive of three cities that each exceeds 100,000 residents, with one of those over 1,000,000. While having such metropolitan neighbors can be a positive thing, such close proximity also makes it incrementally more difficult to retain recent top-quality graduates.

With the ongoing continuous improvement effort in mind, we began to explore the feasibility of establishing a business incubation facility in our town, as a means of helping to solve the brain-drain issue and the lack of high paying jobs. At this point in time, our plan is to contract with a professional firm to determine the feasibility of the project, and to design a thorough implementation plan. We believe it is important to use an outside firm to prepare an external and unbiased evaluation of our community assets and liabilities, which will also help validate the project for contribution purposes. In addition, while we realize that we are limited at this time on a thorough discussion of all the advantages and challenges associated with the business incubator process, our paper is intended to introduce the reader to the concept of a business incubator and to more specifically share our thoughts and ideas of not only how they operate in general, but to use our specific goal of a business incubator in our own economic region to demonstrate why it is a good idea and what it might look like.

\section{WHAT IS BUSINESS INCUBATION, AND WHY USE ONE?}

A business incubator can be analogized to premature infant incubator in a pediatric ward. While the pediatric incubator attempts to nurse a premature infant to a healthy enough state where it can survive on its own, a business incubator can similarly nurture a fledgling company to successful stand-alone survival. As noted in a recent Federal Reserve publication, "Entrepreneurship is the new focal point for rural development" (Drabenstott, Novack and Abraham, 2003).

Business incubators come in a variety of shapes and sizes in our modern economy. According to the National Business Incubation Association (NBIA), there are more than 1,000 business incubator facilities scattered about the United States (NBIA, undated). This is nearly double the 1998 count, and some 83-times the 1980 total (Ibid). Some incubators are affiliated with universities or higher education institutions, while others are not. Some are for profit, but most organize as not-for-profits. Business incubation can be used as a successful economic development strategy. New companies housed in business incubators have an $80 \%$ survival rate, while just $20 \%$ of businesses outside of incubators survive long term (Doescher, 1988). This fact can greatly leverage the success of most economic development programs, particularly in rural communities such as ours. A business incubator can potentially yield huge profits for its owner(s), though this is the exception rather than the rule.

Partnerships between universities and the private sector seem increasingly popular in today's technology savvy society. For example, Stanford University took a risk, betting on Google, Inc. when it was just an idea. This investment has paid of handsomely for the school. The value of Stanford's equity stake in Google, just after the initial public offering, approached $\$ 180$ million (Grimes, 2004).

It is more than just the lure of profit that make business incubator facilities attractive investments for universities, yet surprisingly, less than half of business incubators are sponsored by education institutions. The NBIA estimates that for every dollar of estimated annual operating subsidies, $\$ 45$ in local tax revenue is generated. Additionally, about $84 \%$ of successful incubator "graduates" locate their permanent facility in the same community where they were nurtured (NBIA, undated). One of the proposed ideas for our incubation facility would make regional graduation location a requirement for initial entry into the facility. These reasons, among many, have led us to conclude that investigating our region as a potential site, and our university as a potential sponsor/partner, makes a lot of sense.

\section{SERVICES OFFERED AT AN INCUBATOR}

Business synergy is one of the key advantages to the incubator approach. Others include: cost savings; onsite management coaching; shared best practices; and graduation goal setting. If the feasibility study we commission is 
positive, as we anticipate it will be, we will then concretely consider how the business incubator will look and services it will offer, as we are already doing now on a preliminary basis. We anticipate razing two or three older buildings on the courthouse square area in our downtown, and constructing a two or three-story modern office building. We chose the courthouse square for a strategic political reason. Our town has an active citizen group determined to revitalize the downtown business and retail district. They are in the process of raising funds for what has now become known as the "Campaign for Community Renewal." As of August, 2005 over $\$ 900,000$ of cash and in-kind services has been raised. By choosing to locate this project on the courthouse square, we will immediately be able to attract a solid core of support from the task force group. We suppose this should greatly help build energy and enthusiasm in the local community for the project.

The facility itself will likely be fully wired for high-speed internet access, the cost of which will be included in the monthly rent figure. This is a very important feature to the project as growth in high knowledge industries has outpaced the general economy by 34\% since 1995 (Henderson and Abraham, 2004). Other cost savings for those locating within the facility will also include: access to several shared-use conference rooms, as well as private single offices, and a few office suites. Additionally, several pieces of office equipment would be included in the cost of rent, including: a copy machine, color laser printer, fax and other minor equipment.

We anticipate that management coaching will be another important service provided by our business incubation facility. Our university is fortunate to house a Small Business Development Center (SBDC) located on campus, but it is in an inaccessible, "hidden" building. If financially feasible, we plan to move the SBDC into the first floor of the business incubator, not as facility manager, but rather to provide immediate spontaneous access to management coaching for incubator tenants. Not only would that improve the SBDC's visibility and impact, but it would also be an immediately available resource for the tenants of the incubator to utilize. In addition to such ad-hoc coaching, we envision the SBDC performing regular required management training sessions for incubator tenants, as well as interested parties from around the community.

Incubator tenants will also be able to share discovered best practices, contacts, and other issues with one another. This sense of community will clearly help motivate incubator tenants, as well as provide the opportunity for mentor relationships to develop.

Finally, we feel our incubator lease terms should probably be limited to a maximum of three years, giving tenants a firm target date for financial self-sufficiency. There would be lease contract provisions allowing incubator management to potentially extend lease terms for extraordinary circumstances, but we think the three-year limit should apply to most.

\section{DECIDING WHO GETS IN}

One of the biggest challenges facing incubator managers and directors will be developing the formal process for determining which business proposals have merit, and which do not. The initial screening process would likely involve scanning the cover letter and executive summary of the applicant and making a determination as to the potential "goodness-of-fit" of the proposal. Clearly, incubator managers would drastically cut down on the paperwork from unfit candidates by simply and clearly communicating the criteria for consideration by the managers and directors for inclusion.

In our town, the facility would generally be targeted toward three basic types of businesses: high technology; biopharmaceutical; and basic services. While we may not have any research lab space on site at the incubator facility, tenants would have access to our partner, the university, and its laboratories and the research farm. Service businesses could then fill out the majority of the floor space, generating the rental income necessary to make the incubator financially viable for the sponsoring organization.

Many of these ideas about the look and feel of our proposed business incubator came while conducting a site visit research trip. We discovered a business incubator model that appeared to work very well in a somewhat larger and wealthier urban location, but many of the previously described facility features and functions appear to be 
workable in our community as well. The metropolitan incubator had a similar mix of clients to the mix proposed above, with the exception of a biopharmaceutical presence, which we see as a significant competitive advantage, giving our university's previous commitment to developing a presence in this industry in our region.

In essence, the metropolitan incubator's top-tier clients, those self-described as having the greatest potential to go public, take up just a small part of the total square footage of the facility. While much of the incubator management and coaching was focused on these firms with the highest potential, it was necessary to have a critical mass of other service businesses to help pay the overhead of the facility from the standpoint of financial viability.

\section{SO WHAT?}

This rural incubation case study can be used to augment classroom discussions on the principles of entrepreneurship, business incubation and economic development. It is also significant as a rural revitalization concept that is specifically related to the redevelopment of agricultural communities; to the creation of a successful model for entrepreneurial start-ups; and to the aesthetic enhancement of a downtown central business district. The paper also discusses how the business incubator model can be used to possibly help stem rural population decline. We further discuss some of the nuances present in a business incubator/university partnership.

Using our university's quality commitment as a backdrop, we explain the general process of business incubation, and why it makes sense for communities to use this path to economic growth. We cite important national statistics on entrepreneurial development as well.

Finally, we discuss some of the various services often found in business incubation facilities, including the potential of incorporating our university Small Business Development Center into the design. Lastly, we touch on entry criteria and certain potential restrictions or rules that tenants may likely have to abide with.

\section{CONCLUSIONS}

Clearly, our research to date indicates that a business incubator facility can not only be a strong engine for economic development and job creation, even in a rural marketplace, but that the incubator model creates an environment greatly improving a new enterprise's chance for success. In a rural region, those successes are incredibly important for economic survival. We believe our goal of attempting to graduate an incubating firm within a three-year timetable is realistic, and the research indicates that there is a strong likelihood that those graduated businesses not only have a much greater chance for long-term success but will also remain in the region. This helps alleviate the brain-drain problem discussed earlier and improves the overall economic health of the region. These facts have led us to conclude that a business incubator in our town has not only reasonable chance at success but is essential if we are to attract, create, nurture and grow small businesses and promote entrepreneurship in our region. Additionally, such a facility will provide our "best-and-brightest" students the opportunities to take their ideas and turn them, along with their hard work, in success stories. In the near future, we plan to retain a professional consultant to attempt to validate our assumptions, and we will proceed accordingly when those results are finalized. It is a great challenge, but we believe it is going to be well worth the effort!

\section{REFERENCES}

1. $\quad$ Doescher, William F., (1988) Hatching young companies, Dun and Bradstreet Reports, 36(4).

2. Drabenstott, Mark, Novack, Nancy, and Bridgett Abraham, Main streets of tomorrow: Growing and financing rural entrepreneurs - A conference summary, Federal Reserve Bank of Kansas City - Economic Review, 88(3), 73-85.

3. Grimes, Ann, (2004), Why Stanford is celebrating the Google IPO, The Wall Street Journal, August 23.

4. Henderson, Jason and Bridget Abraham, (2004), Can rural America support a knowledge economy? Federal Reserve Bank of Kansas City - Economic Review, 89(3), 71-95.

5. National Business Incubation Association website, http://www.nbia.org/resource center/bus inc facts/index.php 